https://helda.helsinki.fi

\title{
Winter activity of boreal bats
}

\section{Blomberg, Anna S.}

$2021-10$

Blomberg , A S , Vasko , V , Meierhoferz , M B , Johnson , J S , Eeva , T \& Lilley , T M 2021

, ' Winter activity of boreal bats ' , Mammalian Biology , vol. 101 , no. 5 , pp. 609-618 . https://doi.org/10.1007/s42991

http://hdl.handle.net/10138/338837

https://doi.org/10.1007/s42991-021-00111-8

cc_by

publishedVersion

Downloaded from Helda, University of Helsinki institutional repository.

This is an electronic reprint of the original article.

This reprint may differ from the original in pagination and typographic detail.

Please cite the original version. 


\title{
Winter activity of boreal bats
}

\author{
Anna S. Blomberg ${ }^{1}\left[\right.$ Ville Vasko $^{2} \cdot$ Melissa B. Meierhofer $^{2,3} \cdot$ Joseph S. Johnson $^{4} \cdot$ Tapio Eeva $^{1} \cdot$ Thomas M. Lilley $^{2}$
}

Received: 21 October 2020 / Accepted: 12 February 2021

(c) The Author(s) 2021

\begin{abstract}
Natural hibernation sites used by bats in areas that lack cave features have long remained unresolved. To investigate hibernation site selection and winter activity of boreal bats, we recorded bat calls using passive acoustic monitoring at 16 sites in South-Western Finland. These sites included four rock outcrops with crevices and cave features, three glacial erratics or boulder fields, three ancient shores, three root cellars and three control sites where we did not expect bats to be overwintering. Our results revealed echolocation calls of Eptesicus nilssonii, Plecotus auritus and Myotis sp. We recorded significantly more activity near rock outcrops compared to other habitats, excluding root cellars. We also found that ambient temperature had a positive effect on bat activity and found evidence that $P$. auritus may be using low barometric pressure as a proxy for suitable foraging conditions during the winter. Our results suggest that rock outcrops may be more important to bats than previously acknowledged, highlighting the need to take these sites in account in planning of conservation measures. Furthermore, our findings underline the suitability of using acoustic monitoring in homing on hibernation sites that are not otherwise accessible.
\end{abstract}

Keywords Chiroptera $\cdot$ Hibernation $\cdot$ Winter activity $\cdot$ Acoustic identification $\cdot$ Winter habitat

\section{Introduction}

Insectivorous bats living at high latitudes face enormous fluctuations in the seasonal availability of food. Bats can respond to this challenge either by migrating to warmer areas, where food is occasionally available throughout the winter and hibernation is less risky (Popa-Lisseanu and Voigt 2009), or they can hibernate in situ, by utilizing fat reserves accumulated before the winter (Geiser 2013). The hibernation period of temperate bats can last more than 8 months (Norquay and Willis 2014) and is elapsed in underground hibernation sites, hibernacula. Hibernation consists

Handling editor: Danilo Russo.

Thomas M. Lilley

thomas.lilley@helsinki.fi

1 Department of Biology, University of Turku, Turku, Finland

2 Finnish Museum of Natural History, University of Helsinki, Helsinki, Finland

3 Department of Rangeland, Wildlife and Fisheries Management, Texas A\&M University, College Station, TX, USA

4 Department of Biological Sciences, Ohio University, Athens, OH, USA of extended bouts of torpor, during which bats lower their body temperature close to ambient temperature of the hibernaculum and decrease their metabolic rate (Geiser 2004; Guppy and Withers 2007). Torpor is interrupted with euthermic bouts-arousals-which allow the bat to counter the ecological and physiological costs caused by torpor (Thomas et al. 1990; Humphries et al. 2003; Boyles and Brack 2009; Bouma et al. 2010; Lilley et al. 2017). Arousals are energetically costly, and amount to $80-90 \%$ of total energy expenditure during the winter (Thomas et al. 1990). Due to the long winters at high latitudes, bats must shift their microclimate preference towards colder ambient temperatures and longer torpor bouts to conserve energy (Dunbar and Brigham 2010). Therefore, results of winter activity studies conducted in milder climates, where food is available throughout the winter, are not applicable in the north (Hope and Jones 2012).

During arousals, bats also have an opportunity to drink, copulate and switch places within the hibernaculum (Guilday 1948; Speakman and Racey 1989; Wermundsen and Siivonen 2010). Sometimes bats also leave the hibernation site entirely (Avery 1985; Whitaker and Rissler 1992). While information on the activities that bats undertake outside the hibernaculum is scarce (Boyles et al. 2006), foraging has often been suggested as the primary driver for winter activity 
(Avery 1985; Dunbar et al. 2007; Zahn and Kriner 2016). It is unlikely that aerial hawking bats at northern latitudes are able to feed during the coldest months, as there are almost no nocturnal aerial insects available. However, bats that also glean for terrestrial arthropods have an increased probability of foraging success even during the coldest winter months (Hays et al. 1992; Hope et al. 2014). Bats may also need to relocate to a new hibernaculum during hibernation, which can be due to disturbance, unfavorable changes in abiotic conditions, or a shift in balance between the need to save energy versus minimize cost of torpor (Boyles et al. 2006; Masing and Lutsar 2007; Wermundsen and Siivonen 2010; Johnson et al. 2017). Masing and Lutsar (2007) reported that ambient winter temperatures that are low enough to reduce the temperature inside the hibernacula caused Eptesicus nilssonii to arouse and switch to another hibernaculum, while Myotis daubentonii, M. nattereri and Plecotus auritus found in similar open hibernacula (e.g., small root cellars with missing doors) often froze to death.

Bats can benefit from timing their activity to nights with elevated ambient temperature, as this both increases the probability of flying insects being active (Paige 1995) and leads to a decrease in the energetic costs of activity for the bats (Klüg-Baerwald et al. 2016). Indeed, several studies have reported a positive relationship between bat activity and temperature during the winter (Avery 1985; Zahn and Kriner 2016; Klüg-Baerwald et al. 2016). However, most of the time hibernacula are well protected against changes in outside temperatures, and therefore, bats cannot sense these fluctuations. Unlike the outside temperature, changes in barometric pressure can be detected from inside the hibernaculum. Bats, like many other mammals, can sense changes in barometric pressure and they are known to utilize these cues in many circumstances (Paige 1995; Cryan and Brown 2007; Czenze and Willis 2015). Studies on the effect of barometric pressure on bat activity have reported conflicting results, with some studies describing increased activity with falling or low barometric pressure (Paige 1995; Czenze and Willis 2015), and other studies reporting a positive correlation between bat activity and barometric pressure (Berková and Zukal 2010; Bender and Hartman 2015). The different outcomes likely stem from methodological differences, as well as geographical and seasonal factors affecting both bat ecology and the relationship between weather conditions and barometric pressure.

The geology of Fennoscandia is defined by Svecofennian orogeny, an environment devoid of karst-elements associated with bat hibernacula in scientific literature. The majority of previously known hibernacula in Fennoscandia are anthropogenic (e.g., bunkers, cellars and mines) while very little is known about the use of natural formations as hibernacula. A telemetry study carried out in Norway, found Eptesicus nilssonii and Myotis mystacinus hibernating in rock scree and rock crevices, even though anthropogenic structures suitable for hibernation were also available (Michaelsen et al. 2013). Studies in North America have found bats utilizing natural sites, such as rock crevices, for hibernation (Neubaum et al. 2006; Perry et al. 2010; Johnson et al. 2017; Lemen et al. 2017; Klüg-Baerwald et al. 2017; Neubaum 2018). Johnson et al. (2017) documented bats using ground level rock crevices, rock walls, scree slopes and rock fields also during late autumn. Currently there are no estimates on the population sizes of bats in Finland but, given that only some thousands of bats are observed during the census each winter, it is likely that most bats hibernate in yet unidentified sites. Due to the glacial history and geology of Finland, there is a strong likelihood these hibernation sites are associated with a variety of rock formations. Because of the probability of attempting to forage or shift hibernacula during the hibernation period described above, acoustic monitoring in the vicinity of potential sites could provide a means to gather information on the nature of sites that are utilized by bats.

Of the eight bat species known to overwinter in Finland (Siivonen and Wermundsen 2008; Wermundsen and Siivonen 2010; Blomberg et al. 2020), five, including $E$. nilssonii, $P$. auritus, Myotis daubentonii, $M$. brandtii and M. mystacinus are considered common in South-Western Finland, where we conducted our study (Tidenberg et al. 2019; Vasko et al. 2020). To study the use of natural rock formations as hibernacula and factors affecting the winter activity of these boreal bats, we conducted acoustic monitoring of bat activity at locations we suspected were suitable hibernation sites. Our monitoring was conducted across all seasons to highlight winter activity at the sites. We selected our sites based on the findings in Norway (Michaelsen et al. 2013) and North America (Lausen and Barclay 2006; Johnson et al. 2016; Klüg-Baerwald et al. 2017). To augment these, we used anecdotal evidence of bats hibernating in boulder fields in Ostrobothnia and our previous knowledge of root cellars and some caves being used by bats in the winter. The abiotic conditions of the hibernacula affect the overwintering success of bats (Boyles and Brack 2009). Finding suitable hibernacula is vital for the survival of bats in colder climates, which is why we can predict that the location of hibernacula determines much of the spatial distribution of bats during the winter. Therefore, we consider bat activity at a given location to be a proxy for hibernation sites.

We predicted that we would detect more bat activity during the winter months outside potential natural hibernation sites (ancient shores, rock outcrops, and glacial erratic formations) and root cellars compared to sites that do not have geological formations or structures suitable for hibernation. Second, we predicted that bats would be more active during warm nights, when insect food is more likely to be available (Avery 1985; Zahn and Kriner 2016). We also predicted that 
low barometric pressure increases bat activity. During the winter, barometric pressure can function as a proxy for mild outside temperature, which bats can sense from within their hibernacula (Paige 1995; Czenze and Willis 2015). Finally, we predicted E. nilssonii and P. auritus would be more active during the winter compared to Myotis species. Due to their higher mass and proportional fat-stores, these species can attempt to minimize the negative physiological effects of hibernation by arousing more frequently (Boyles et al. 2020). Therefore, the probability of encountering E. nilssonii or $P$. auritus during the winter is higher than encountering Myotis, although all bats most likely utilize activity to drink, forage or switch between hibernacula.

\section{Materials and methods}

\section{Acoustic monitoring}

We monitored year-round bat activity at 16 sites in southwestern Finland using 11 SongMeter SM2 + BAT (Wildlife Acoustics) and 4 AnaBat SD2 (Titley Scientific) passive detectors from 12 November 2017 to 31 April 2019. The two different types of recorder were evenly distributed across monitoring site classes to avoid sampling bias. Monitoring site classes selected for the studies included ancient shores $(N=3)$, rock outcrops with caves and/or crack features ( $N=4$, Fig. 1), glacial erratic formations or boulder fields $(N=3)$, and root cellars $(N=3)$, of which the latter were known to be used by bats during the winter as hibernation sites. Ancient shores are post-glacial rebounds, upthrusts, where the continuously rising land causes the
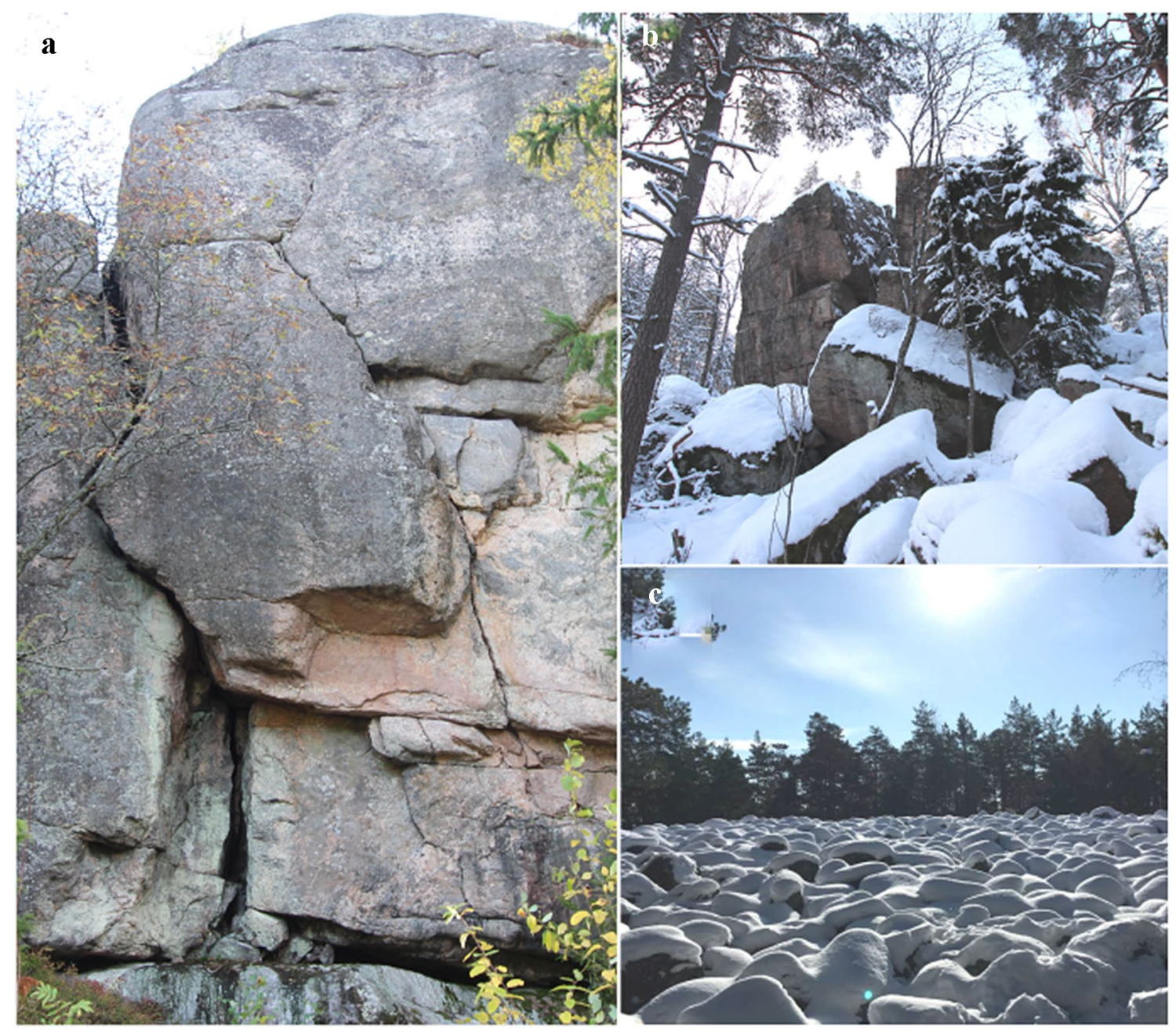

Fig. 1 Geological formations monitored for bat activity over two consecutive winters included a rock outcrops, $\mathbf{b}$ glacial erratics, and $\mathbf{c}$ ancient shores 
sea to retreat further from the continent leaving rocks and pebbles (approximate $\phi=50-100 \mathrm{~cm}$ ) where the seashore resided historically. The group consisting of glacial erratics or boulder fields included two glacial erratics, which in our case consisted of multiple glacially deposited rocks differing in size and type of rock native to the area in which they rest, and one anthropogenic boulder field, covered by large residual rocks from an old quarry. In all the above-mentioned environments, the potential hibernation sites are in crevices under the rocks. Feeding sites $(N=3)$ used by bats in the summer were used as control sites for the study (Fig. 2). These sites were devoid of geological features in the immediate surroundings. All sites were selected based on their potential suitability for bats and accessibility for research purposes, because during the coldest and darkest period of winter, the batteries in the devices had to be changed every other week. At the sites, we placed microphones at $1.5-\mathrm{m}$ height on a tree or a pole in semi-open environment with enough flying space for the bats.

We programmed the SongMeters to begin monitoring half an hour before sunset and end monitoring half an hour after the sunrise. We adjusted the monitoring schedule of the AnaBats manually each month so that it matched the schedule of the SongMeters. We collected the data in WAV format (SongMeters) and ZeroCrossing format (AnaBats). Due to the harsh weather conditions, all multidirectional ultrasound microphones were fitted with a protective covering to keep them from getting wet or covered with snow. We used SMX-US microphones for the SongMeters and tested their sensitivity both before and after the monitoring. Microphones with sensitivity below $-15 \mathrm{~dB}$ at $40 \mathrm{kHz}$ were not used, as recommended by the manufacturer. The AnaBats were tested by comparing them with a SongMeter in a side-by-side setup for two nights before and after the study. We obtained weather data from the Finnish Meteorological Institute. For the analysis, we used weather data from the closest weather station to the survey sites (Fig. 2).

\section{Species identification}

We used Kaleidoscope Pro (Version 5.3.8., Wildlife Acoustics) for filtering and organizing the data. We chose not to discard non-bat (noise) files suggested by the program from wintertime to ensure that all recorded bat calls were included in the analysis. From the summer months, noise files were discarded, because checking them manually would have been too laborious. After initial filtering, we then manually viewed acoustic files and identified species. Due to the uncertainty of identifying Myotis to species level, we chose to pool all recordings of the genus Myotis for analysis.
Fig. 2 Map of study area. White circles $=$ control sites, white squares $=$ root cellars, black circles $=$ ancient shores, black squares $=$ outcrops, black triangles $=$ glacial erratics, star $=$ weather station

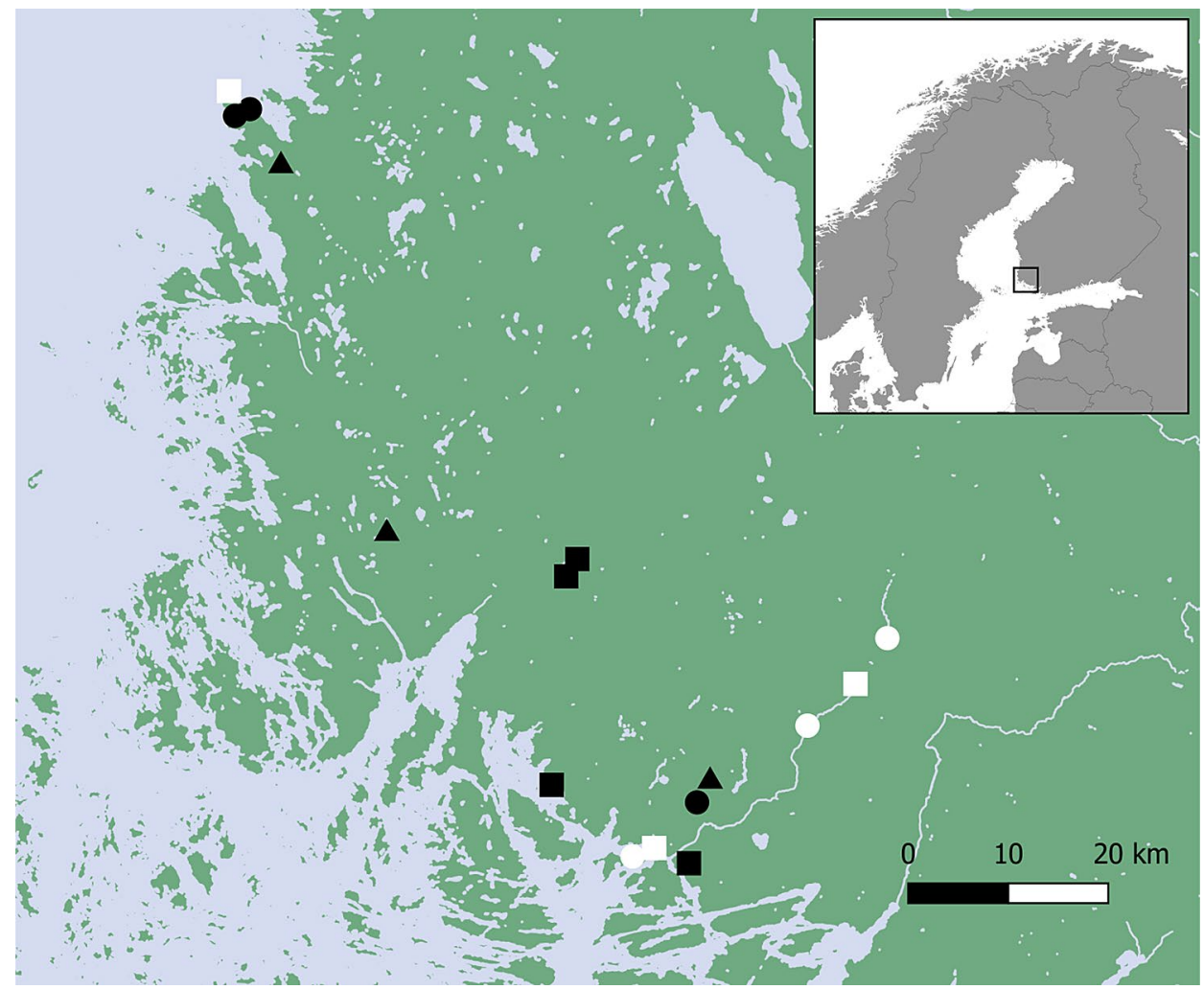




\section{Statistical analysis}

We considered winter months as those from November to March (Finnish Meteorological Institute). All together, we recorded 53656 hours of audio data during the two winters for all sites. We gathered $35 \mathrm{~min}$ of Myotis activity, 182 min of E. nilssonii activity and 66 min of P. auritus activity. We investigated the differences in bat activity between sites, habitats and species during the winter with a generalized linear mixed model (Proc GLIMMIX in SAS, SAS Institute Inc. 2013). In the model, we used normal error distribution with identity link function. For each site, we calculated a monthly activity index for $E$. nilssonii, $P$. auritus and pooled Myotis species by dividing the number of active minutes (minutes with bat activity) by the number of total recorded hours (number of hours the equipment was recording and functioning properly). This was done to account for any interruptions caused by battery failures. We used this activity index with a $\log _{10}$-transformation as the response variable and species, habitat type and site nested under habitat type as fixed effects. In cases where we recorded zero minutes during a month at a site, we replaced the zero with $0.001 \mathrm{~min}$ to conduct the $\log _{10}$-transformation for the activity index. The $\mathrm{F}$ test statistic measures the ratio of explained variance to unexplained variance ( $F=$ factor mean square/error mean square). We also investigated the differences in activity between habitats and species using the Tukey-Kramer method.

Furthermore, we investigated the effect of ambient temperature and barometric pressure on the activity of E. nilssonii, $P$. auritus and the pooled set of Myotis species, and all bat activities (all species pooled) using generalized linear models. We used the mean ambient temperature and mean barometric pressure of the previous $24 \mathrm{~h}$, as well as their interaction as explanatory variables. We used mean barometric pressure of the previous $24 \mathrm{~h}$, as low barometric pressure in the winter brings cloudy and rainy, yet mild weather to our study area. We standardized all fixed factors prior to analysis and checked for multicollinearity using variance inflation factors (VIFs). VIFs were $<3$ in all instances, suggesting that no or very minimal multicollinearity between fixed factors existed. We used backward stepwise model selection, retaining the variables that produced the lowest AIC-values, to select the best model for each species and species group. We considered $P$ values $<0.05$ significant for all tests.

\section{Results}

Levels of bat activity differed between habitats $\left(F_{(4,405)}=9.91 ; P<0.001\right)$, species $\left(F_{(2,405)}=19.29\right.$; $P<0.001)$ and sites $\left(F_{(11,405)}=2.11 ; P=0.019\right)$. Most bat activity during the winter took place at rock outcrops (Table 1). Rock outcrops had significantly more bat activity than ancient shores $(t=4.51 ; d f=405 ; P<0.001)$, glacial erratics $(t=4.19 ; d f=405 ; P<0.001)$ and control sites $(t=5.09 ; d f=405 ; P<0.001)$. Second highest activity was measured outside root cellars, in which we previously knew bats were overwintering. Root cellars had significantly more activity in the winter than control sites, which were selected because they were known foraging areas in the summer $(t=3.29 ; d f=405 ; P=0.01)$. The difference in activity between root cellars and ancient shores approached statistical significance $(t=2.67 ; d f=405 ; P=0.06)$. Furthermore, our results revealed significantly more calls of E. nilssonii $(N=182)$ than $P$. auritus $(N=66 ; t=5.17 ; d f=405$; $P<0.001)$ and Myotis species $(N=34 ; t=5.56 ; d f=405$; $P<0.001$; Table 2).

Total bat activity increased with higher ambient temperature and barometric pressure (Table 3). However, we found that total activity decreased faster with decreasing temperatures if barometric pressure was low (Fig. 3a). Activity of E. nilssonii was positively affected by increasing barometric

Table 1 Differences of LS-means for total bat activity measured at different habitats during the winter

\begin{tabular}{|c|c|c|c|c|c|c|c|c|c|c|c|c|}
\hline Habitat & Habitat & Estimate & SE & DF & $t$ Value & $\operatorname{Pr}>|t|$ & Adj $P$ & Alpha & Lower & Upper & Adj lower & Adj upper \\
\hline Ancient shore & Outcrop & -0.991 & 0.219 & 405 & -4.51 & $<0.001$ & $<0.001$ & 0.05 & -1.423 & -0.559 & -1.593 & -0.389 \\
\hline Ancient shore & Glacial erratic & -0.034 & 0.243 & 405 & -0.14 & 0.889 & 0.910 & 0.05 & -0.513 & 0.444 & -0.701 & 0.633 \\
\hline Ancient shore & Root cellar & -0.738 & 0.276 & 405 & -2.67 & 0.008 & 0.060 & 0.05 & -1.280 & -0.195 & -1.494 & 0.020 \\
\hline Ancient shore & Control site & 0.217 & 0.252 & 405 & 0.86 & 0.390 & 0.911 & 0.05 & -0.278 & 0.711 & -0.473 & 0.906 \\
\hline Outcrop & Glacial erratic & 0.957 & 0.228 & 405 & 4.19 & $<0.001$ & $<0.001$ & 0.05 & 0.508 & 1.406 & 0.331 & 1.582 \\
\hline Outcrop & Root cellar & 0.253 & 0.263 & 405 & 0.96 & 0.336 & 0.871 & 0.05 & -0.263 & 0.770 & -0.467 & 0.974 \\
\hline Outcrop & Control site & 1.207 & 0.237 & 405 & 5.09 & $<0.001$ & $<0.001$ & 0.05 & 0.741 & 1.674 & 0.558 & 1.857 \\
\hline Glacial erratic & Root cellar & -0.703 & 0.283 & 405 & -2.49 & 0.013 & 0.096 & 0.05 & -1.260 & -0.147 & -1.479 & 0.072 \\
\hline Glacial erratic & Control site & 0.251 & 0.259 & 405 & 0.97 & 0.334 & 0.870 & 0.05 & -0.259 & 0.760 & -0.459 & 0.961 \\
\hline Root cellar & Control site & 0.954 & 0.290 & 405 & 3.29 & 0.001 & 0.010 & 0.05 & 0.384 & 1.524 & 0.159 & 1.749 \\
\hline
\end{tabular}

Bat activity was measured at each site with a monthly activity index (minutes with recordings/number of recorded hours) 
Table 2 Differences of LS-means for monthly activity indexes of Eptesicus nilssonii, Plecotus auritus and a pooled set of Myotis species (M. daubentonii, M. brandtii, M. mystacinus, and $M$. nattereri) recorded during the winter

\begin{tabular}{llrlrrrrrrrrr}
\hline Species & Species & Estimate & SE & $d f$ & $t$ Value & Pr $>|t|$ & Adj $P$ & Alpha & Lower & Upper & Adj lower & Adj upper \\
\hline E. nilssonii & Myotis sp & 1.028 & 0.185 & 405 & 5.56 & $<0.001$ & $<0.001$ & 0.05 & 0.665 & 1.391 & 0.593 & 1.462 \\
E. nilssonii & P. auritus & 0.955 & 0.185 & 405 & 5.17 & $<0.001$ & $<0.001$ & 0.05 & 0.592 & 1.318 & 0.521 & 1.389 \\
Myotis sp & P. auritus & -0.073 & 0.185 & 405 & -0.39 & 0.694 & 0.918 & 0.05 & -0.436 & 0.290 & -0.507 & 0.362 \\
\hline
\end{tabular}

Table 3 Results of generalized linear model on the effect of weather conditions on total bat activity $(N=318 \mathrm{~min}$ with activity), activity of Eptesicus nilssonii $(N=182$ min with activity), activity of Plecotus auritus $(N=66$ min with activity) and activity of Myotis sp. (pooled for four species; M. daubentonii, M. brandtii, M. mystacinus, $M$. nattereri, $N=35$ min with activity)

\begin{tabular}{llrrrr}
\hline Species & Weather variable & Estimate & Std. error & $z$ value & $\operatorname{Pr}(>|z|)$ \\
\hline Total bat activity & (Intercept) & -2.092 & 0.078 & -26.650 & $<0.001$ \\
Total bat activity & Temperature & 0.982 & 0.092 & 10.649 & $<0.001$ \\
Total bat activity & Barometric pressure & 0.292 & 0.073 & 3.996 & $<0.001$ \\
Total bat activity & Temperature:pressure & -0.166 & 0.074 & -2.240 & 0.025 \\
E. nilssonii & (Intercept) & -3.281 & 0.128 & -25.542 & $<0.001$ \\
E. nilssonii & Temperature & 0.859 & 0.139 & 6.192 & $<0.001$ \\
E. nilssonii & Barometric pressure & 0.232 & 0.123 & 1.880 & 0.06 \\
P. auritus & (Intercept) & -5.319 & 0.444 & -11.982 & $<0.001$ \\
P. auritus & Temperature & 2.010 & 0.529 & 3.800 & $<0.001$ \\
P. auritus & Barometric pressure & 0.910 & 0.359 & 2.536 & 0.01 \\
P. auritus & Temperature:pressure & -1.434 & 0.331 & -4.338 & $<0.001$ \\
Pooled Myotis & (Intercept) & -5.031 & 0.272 & -18.504 & $<0.001$ \\
Pooled Myotis & Temperature & 0.663 & 0.307 & 2.162 & 0.031 \\
Pooled Myotis & Pressure & 0.245 & 0.293 & 0.834 & 0.404 \\
Pooled Myotis & Temperature:pressure & 0.726 & 0.337 & 2.156 & 0.031 \\
\hline
\end{tabular}

pressure and ambient temperature (Table 3). Similar to $E$. nilssonii, the activity of $P$. auritus increased with higher mean ambient temperature (Table 3). The effect of temperature on the activity of $P$. auritus was stronger at low barometric pressure (Fig. 3b). Contrary to $P$. auritus, the activity of Myotis species increased more steeply with ambient temperature at high barometric pressure (Fig. 3c). The lowest hourly temperature where a bat was recorded was $-9.8^{\circ} \mathrm{C}$ (E. nilssonii). The lowest temperature for the Myotis and $P$. auritus were -3.1 and $-5.6^{\circ} \mathrm{C}$, respectively.

\section{Discussion}

Our results revealed greater bat activity at rock outcrops compared to root cellars, which have been considered one of the most important hibernacula in many areas of the boreal zone (Rydell 1989; Lesiński et al. 2004; Vintulis and Pētersons 2014). Rock outcrops and boulder fields constitute up to $2.5 \%$ of Finland's land area (Kontula et al. 2018). Most of these are located in South-Western Finland, making them available as hibernacula to bats in our study area. However, the utilization of other natural sites in Fennoscandia should be considered in more detail (although, see Michaelsen et al. 2013). Almost all of the hibernation sites known in Finland prior to this study are manmade, but the number of individuals observed at these sites each winter likely resembles only a fraction of the true populations (Wermundsen and Siivonen 2010). Our results suggest that natural formations may be more important to hibernating bats than previously considered.

Eptesicus nilssonii were observed significantly more often than pooled Myotis species or P. auritus. The species is well adapted to the cold and long winters of the north, hibernating in colder environments than other species, leading to longer bouts of torpor which help them save more energy (Anufriev and Revin 2006; Siivonen and Wermundsen 2008). Furthermore, E. nilssonii have a higher body mass than P. auritus and Myotis species, which enables them with greater fat reserves for the winter (Rydell 1993). Larger body size further increases energy saving through relatively lower levels of heat loss, as their surface area to volume ratio is lower (Worthy and Edwards 1990). These factors may allow E. nilssonii to spend more energy on locomotion during the winter and permit them to forage when conditions are suitable. Lausen and Barclay (2006) reported a similar pattern of higher activity of Eptesicus fuscus compared to Myotis species during the winter in Canada.

While our results can indicate that E. nilssonii are more active during the winter compared to the other species 
Fig. 3 Effect of ambient temperature on a the total winter bat activity $(N=318$ min with activity) $\mathbf{b}$ activity of Plecotus auritus $(N=66 \mathrm{~min}$ with activity) and c Myotis species (pooled for four species; M. daubentonii, M. brandtii, $M$. mystacinus, $M$. nattereri, $N=35$ min with activity) in different mean barometric pressures. Unit for activity is the predicted number of minutes with recordings/night. Shaded areas represent $95 \%$ confident intervals. Temperature and barometric pressure are mean values of previous $24 \mathrm{~h}$
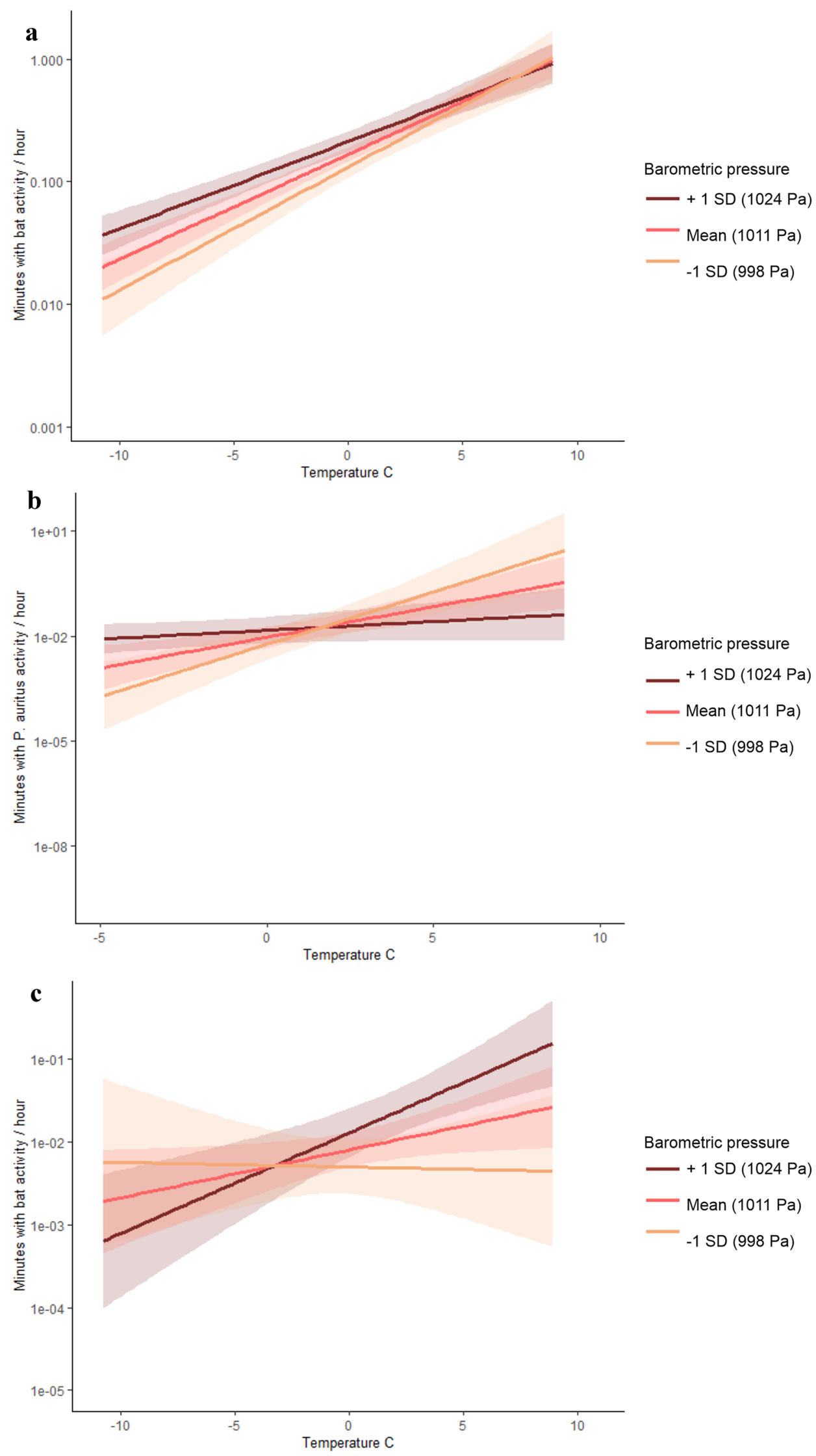

Barometric pressure

- 1 SD (1024 Pa)

- Mean (1011 Pa)

$-1 \mathrm{SD}(998 \mathrm{~Pa})$

Barometric pressure

- +1 SD (1024 Pa)

- Mean (1011 Pa)

$-1 \mathrm{SD}(998 \mathrm{~Pa})$ 
monitored, it is important to note that this difference may also be explained by other factors. Currently, there are no estimates on population sizes of bats in Finland, and we, therefore, cannot determine whether our results are indeed reflecting differences in the activity or population size, or differences in hibernation habitat preferences. Furthermore, the acoustic detectability varies between the species. Detectability is influenced by the intensity of calls as well as the frequency, as high frequency sounds attenuate more quickly in the atmosphere (Griffin and Galambos 1941; Lawrence and Simmons 1982), leading to species such as E. nilssonii with high intensity and low frequency calls having a higher probability of occurring in acoustic data compared to species with higher pitch and/or more faint calls (Schnitzler and Kalko 2001). Bat species also differ in their preference for abiotic conditions of the hibernacula and it is known that both E. nilssonii and P. auritus often hibernate in conditions that are colder and less humid than conditions preferred by many Myotis species (Wermundsen and Siivonen 2010). Given the ability of E. nilssonii to take advantage of hibernacula not suitable for other species (Masing and Lutsar 2007), it is also possible that the hibernacula studied here are not suitable for species requiring higher ambient humidity and temperature. For instance, we cannot disclose the possibility that other hibernation habitats, not included in our study, may be more suitable for Myotis species.

We predicted that ambient temperature would have a positive effect on bat activity, and that activity would be greater at low barometric pressure. In accordance with our hypothesis, we found that an increase in ambient temperature had a positive effect on the activity of $E$. nilssonii, $P$. auritus and Myotis species during the winter months. Furthermore, we found that total bat activity as well as the activity of $P$. auritus increased more rapidly with rising ambient temperature when barometric pressure was low. In Finland, low-pressure systems during the winter often conjure mild temperatures together with cloudy, rainy weather, while high pressure systems usually arrive from the east, bringing cold yet clear weather (Similä 1981). We suggest that this result indicates that in general, bats may indeed use low barometric pressure as a proxy for suitable conditions to leave the hibernaculum, leading them to be more active during warm, often cloudy, nights. Due to the siting of our passive detectors and the structure of most of the habitats studied, with no single, obvious entrance to the hibernacula, we were likely to only record bats that left the hibernacula entirely and continued flying outside for a period of time. Because P. auritus is known to forage during the winter (Hays et al. 1992), we suggest that this species may benefit from detecting changes in barometric pressure from within the hibernaculum. In contrast, we found that activity of Myotis species increased more rapidly with temperature in high barometric pressure, while the activity of $E$. nilssonii increased in high barometric pressure. We propose that these results show that the activity of Myotis species and E. nilssonii is determined rather by the timing of their arousals than by foraging possibilities.

We suggest that a proportion of the winter activity we recorded was due to bats relocating to different hibernacula. Bats can benefit from timing these movements to warm nights, as this leads to reduced energy loss, corresponding with our model predicting more activity at warm ambient temperature (Klüg-Baerwald et al. 2016). E. nilssonii may be more prone to shifting between hibernation sites compared to Myotis, as suggested by Masing and Lutsar (2007). This is due to the larger body size and fat reserves of the species, which enables more energy to be allocated to activity. This is consistent with our result of $E$. nilssonii being active in colder temperatures than Myotis species.

In addition to their abundance, sites such as rock outcrop formations may offer additional advantages. For instance, it is likely that human disturbance is scarce, if nonexistent, in these environments compared to root cellars, bunkers, and other anthropogenic structures. Furthermore, Michaelsen et al. (2013) suggested that using hibernacula such as rock scree might help bats avoid predators during hibernation and emergence. Despite the acoustic evidence of bat activity in many locations, we only found a single hibernating bat in the natural study sites ( $M$. brandtii inside a cave at a rock outcrop), which highlights the difficulty of visually observing hibernating bats in areas that lack large caves. Our results indicate that hibernation sites not accessible to humans, and thus understudied, are more important for bats than previously acknowledged. Most research on hibernation behavior thus far has been conducted on species that hibernate in caves in karst regions, often in large numbers, leaving the majority of species not encountered in these environments understudied. Recently, the use of acoustic monitoring and studies utilizing temperature sensing radio tags has brought new insight to the hibernation behavior of more elusive species (e.g., Lausen and Barclay 2006; Lemen et al. 2017; Ossa et al. 2020), to which our results add. However, climate change may affect the usability of these sites for bats, as the loss of snow cover is likely to have a great impact on the microclimates of these hibernacula. Furthermore, our results also highlight the need of taking bats into account in land use, when sites with rock outcrops are altered.

Supplementary Information The online version contains supplementary material available at https://doi.org/10.1007/s42991-021-00111-8.

Acknowledgements The study was funded by Kone foundation (Grant number 201710231), Emil Aaltonen foundation and H2020 Marie Sklodowska-Curie Actions (Grant number 706196). We thank Rauno Varjonen for maintaining the SongMeter in Vehmaa and Sari Haartonen from the Finnish Meteorological institute for her kind help in gathering the weather data. 
Author contributions ASB, TML, VV and TE designed the study; ASB and VV collected the data; ASB, VV, TE and MBM analyzed the data; ASB wrote the first draft of the manuscript; JSJ edited the first draft; all the authors contributed to the final version.

Funding Open access funding provided by University of Turku (UTU) including Turku University Central Hospital. This study was funded by Kone foundation, Emil Aaltonen foundation, and H2020 Marie Sklodowska-Curie Actions.

Availability of data and material The datasets generated during and/or analyzed during the current study are available in Dryad, https://doi. org/10.5061/dryad.zgmsbcc9w.

Code availability The code used in the analysis during the current study is available from the corresponding author upon request.

\section{Compliance with ethical standards}

Conflict of interest The authors declare that there is no conflict of interest.

Ethics approval Not applicable.

Consent to participate Not applicable.

Consent for publication Not applicable.

Open Access This article is licensed under a Creative Commons Attribution 4.0 International License, which permits use, sharing, adaptation, distribution and reproduction in any medium or format, as long as you give appropriate credit to the original author(s) and the source, provide a link to the Creative Commons licence, and indicate if changes were made. The images or other third party material in this article are included in the article's Creative Commons licence, unless indicated otherwise in a credit line to the material. If material is not included in the article's Creative Commons licence and your intended use is not permitted by statutory regulation or exceeds the permitted use, you will need to obtain permission directly from the copyright holder. To view a copy of this licence, visit http://creativecommons.org/licenses/by/4.0/.

\section{References}

Anufriev AI, Revin YV (2006) Bioenergetics of hibernating bats (Chiroptera, Vespertilionidae) in Yakutia. Plecotus et al 9:8-17

Avery MI (1985) Winter activity of Pipistrelle Bats. J Anim Ecol 54:721-738. https://doi.org/10.2307/4374

Bender MJ, Hartman GD (2015) Bat activity increases with barometric pressure and temperature during autumn in central Georgia. Southeast Nat 14:231-242. https://doi.org/10.1656/058.014.0203

Berková $\mathrm{H}$, Zukal J (2010) Cave visitation by temperate zone bats: effects of climatic factors. J Zool 280:387-395. https://doi.org/ 10.1111/j.1469-7998.2009.00673.x

Blomberg AS, Vasko V, Salonen S et al (2020) First record of a Nathusius' pipistrelle (Pipistrellus nathusii) overwintering at a latitude above $60^{\circ} \mathrm{N}$. Mammalia 85:74-78. https://doi.org/10.1515/ mammalia-2020-0019

Bouma HR, Carey HV, Kroese FGM (2010) Hibernation: the immune system at rest? J Leukoc Biol 88:619-624. https://doi.org/10.1189/ jlb.0310174
Boyles JG, Brack V (2009) Modeling survival rates of hibernating mammals with individual-based models of energy expenditure. $\mathbf{J}$ Mammal 90:9-16. https://doi.org/10.1644/08-MAMM-A-205.1

Boyles JG, Dunbar MB, Whitaker JO (2006) Activity following arousal in winter in North American vespertilionid bats. Mammal Rev 36:267-280. https://doi.org/10.1111/j.1365-2907.2006.00095.x

Boyles JG, Johnson JS, Blomberg A, Lilley TM (2020) Optimal hibernation theory. Mammal Rev 50:91-100

Cryan P, Brown A (2007) Migration of bats past a remote island offers clues toward the problem of bat fatalities at wind turbines. Biol Conserv 139:1-11. https://doi.org/10.1016/j.biocon.2007.05.019

Czenze ZJ, Willis CKR (2015) Warming up and shipping out: arousal and emergence timing in hibernating little brown bats (Myotis lucifugus). J Comp Physiol B 185:575-586. https://doi.org/10. 1007/s00360-015-0900-1

Dunbar MB, Brigham RM (2010) Thermoregulatory variation among populations of bats along a latitudinal gradient. J Comp Physiol B 180:885-893. https://doi.org/10.1007/s00360-010-0457-y

Dunbar MB, Whitaker JO, Robbins LW (2007) Winter feeding by bats in Missouri. Acta Chiropterologica 9:305-310. https://doi.org/10. 3161/1733-5329(2007)9[305:WFBBIM]2.0.CO;2

Geiser F (2004) Metabolic rate and body temperature reduction during hibernation and daily torpor. Annu Rev Physiol 66:239-274. https://doi.org/10.1146/annurev.physiol.66.032102.115105

Geiser F (2013) Hibernation. Curr Biol 23:R188-R193. https://doi.org/ 10.1016/j.cub.2013.01.062

Griffin DR, Galambos R (1941) The sensory basis of obstacle avoidance by flying bats. J Exp Zool 86:481-506. https://doi.org/10. 1002/jez.1400860310

Guilday JE (1948) Little brown bats copulating in winter. J Mammal 29:416-417

Guppy M, Withers P (2007) Metabolic depression in animals: physiological perspectives and biochemical generalizations. Biol Rev 74:1-40. https://doi.org/10.1111/j.1469-185X.1999.tb00180.x

Hays GC, Speakman JR, Webb PI (1992) Why do brown long-eared bats (Plecotus auritus) fly in winter? Physiol Zool 65:554-567

Hope PR, Jones G (2012) Warming up for dinner: torpor and arousal in hibernating Natterer's bats (Myotis nattereri) studied by radio telemetry. J Comp Physiol B 182:569-578. https://doi.org/10. 1007/s00360-011-0631-x

Hope PR, Bohmann K, Gilbert MTP, Zepeda-Mendoza ML, Razgour O, Jones G (2014) Second generation sequencing and morphological faecal analysis reveal unexpected foraging behaviour by Myotis nattereri (Chiroptera, Vespertilionidae) in winter. Front Zool 11:39. https://doi.org/10.1186/1742-9994-11-39

Humphries MM, Kramer DL, Thomas DW (2003) The role of energy availability in Mammalian hibernation: an experimental test in free-ranging eastern chipmunks. Physiol Biochem Zool 76:180 186. https://doi.org/10.1086/367949

Johnson JS, Scafini M, Sewall BJ, Turner GG (2016) Hibernating bat species in Pennsylvania use colder winter habitats following the arrival of white-nose syndrome. In: Butchkoski CM, Reeder DM, Turner GG, Whidden HP (eds) Conservation and ecology of Pennsylvania's bats. The Pennsylvania Academy of Sciences, pp 181-199

Johnson JS, Treanor JJ, Lacki MJ et al (2017) Migratory and winter activity of bats in Yellowstone National Park. J Mammal 98:211221. https://doi.org/10.1093/jmammal/gyw175

Klüg-Baerwald BJ, Gower LE, Lausen CL, Brigham RM (2016) Environmental correlates and energetics of winter flight by bats in southern Alberta, Canada. Can J Zool 94:829-836. https://doi. org/10.1139/cjz-2016-0055

Klüg-Baerwald BJ, Lausen CL, Willis CKR, Brigham RM (2017) Home is where you hang your bat: winter roost selection by prairie-living big brown bats. J Mammal 98:752-760. https://doi.org/ 10.1093/jmammal/gyx039 
Kontula T, Teeriaho J, Jukka H, et al (2018) Kalliot ja kivikot. In: Suomen luontotyyppien uhanalaisuus 2018 : Luontotyyppien punainen kirja. Osa 2: Luontotyyppien kuvaukset. Ympäristöministeriö: Suomen ympäristökeskus, Helsinki.

Lausen CL, Barclay RMR (2006) Winter bat activity in the Canadian prairies. Can J Zool 84:1079-1086. https://doi.org/10.1139/ z06-093

Lawrence B, Simmons J (1982) Echolocation in bats: the external ear and perception of the vertical positions of targets. Science 218:481-483. https://doi.org/10.1126/science.7123247

Lemen CA, Freeman PW, White JA (2017) Acoustic evidence of bats using rock crevices in winter: a call for more research on winter roosts in North America. Trans Neb Acad Sci Affil Soc 36:9-13. https://doi.org/10.13014/K2SF2T3Q

Lesiński G, Kowalski M, Domański J et al (2004) The importance of small cellars to bat hibernation in Poland. Mammalia 68:345-352. https://doi.org/10.1515/mamm.2004.034

Lilley TM, Prokkola JM, Johnson JS et al (2017) Immune responses in hibernating little brown myotis (Myotis lucifugus) with white-nose syndrome. Proc R Soc B Biol Sci 284:20162232. https://doi.org/ 10.1098/rspb.2016.2232

Masing M, Lutsar L (2007) Hibernation temperatures in seven species of sedentary bats (Chiroptera) in Northeastern Europe. Acta Zool Litu 17:47-55. https://doi.org/10.1080/13921657.2007.10512815

Michaelsen TC, Olsen O, Grimstad KJ (2013) Roosts used by bats in late autumn and winter at northern latitudes in Norway. Folia Zool 62:297-304. https://doi.org/10.25225/fozo.v62.i4.a7.2013

Neubaum DJ (2018) Unsuspected retreats: autumn transitional roosts and presumed winter hibernacula of little brown myotis in Colorado. J Mammal. https://doi.org/10.1093/jmammal/gyy120

Neubaum DJ, O'Shea TJ, Wilson KR (2006) Autumn migration and selection of rock crevices as hibernacula by big brown bats in Colorado. J Mammal 87:470-479. https://doi.org/10.1644/ 05-MAMM-A-252R1.1

Norquay KJO, Willis CKR (2014) Hibernation phenology of Myotis lucifugus: hibernation phenology of Myotis lucifugus. J Zool 294:85-92. https://doi.org/10.1111/jzo.12155

Ossa G, Lilley TM, Waag AG et al (2020) Roosting ecology of the southernmost bats, Myotis chiloensis and Histiotus magellanicusa, in southern Tierra del Fuego, Chile. Austral Ecol 45:1169-1178. https://doi.org/10.1111/aec.12950

Paige KN (1995) Bats and barometric pressure: conserving limited energy and tracking insects from the roost. Funct Ecol 9:463-467. https://doi.org/10.2307/2390010

Perry RW, Saugey DA, Crump BG (2010) Winter roosting ecology of silver-haired bats in an Arkansas forest. Southeast Nat 9:563-572. https://doi.org/10.1656/058.009.0313

Popa-Lisseanu AG, Voigt CC (2009) Bats on the move. J Mammal 90:1283-1289. https://doi.org/10.1644/09-MAMM-S-130R2.1

Rydell J (1989) Cellars as hibernation sites for bats. Fauna Och Flora Naturhistoriska Riksmuseet 84:49-53
Rydell J (1993) Eptesicus nilssonii. Mamm Species 430:1-7. https:// doi.org/10.2307/3504128

SAS Institute Inc (2013) Base SAS 9.4 procedures guide: statistical procedures. SAS Institute and Inc., Cary

Schnitzler H-U, Kalko EKV (2001) Echolocation by insect-eating bats. Bioscience 51:557-569. https://doi.org/10.1641/0006-3568(2001) 051[0557:EBIEB]2.0.CO;2

Siivonen Y, Wermundsen T (2008) Characteristics of winter roosts of bat species in southern Finland. Mammalia 72:50-56. https://doi. org/10.1515/MAMM.2008.003

Similä A (1981) Artturi Similän sääkirja. WSOY, Helsinki

Speakman JR, Racey PA (1989) Hibernal ecology of the pipistrelle bat: energy expenditure, water requirements and mass loss, implications for survival and the function of winter emergence flights. J Anim Ecol 58:797-813

Thomas DW, Dorais M, Bergeron J-M (1990) Winter energy budgets and cost of arousals for hibernating little brown bats, Myotis lucifugus. J Mammal 71:475-479. https://doi.org/10.2307/13819 67

Tidenberg E-M, Liukko U-M, Stjernberg T (2019) Atlas of Finnish Bats. Ann Zool Fenn 56:207-250. https://doi.org/10.5735/086. 056.0117

Vasko V, Blomberg AS, Vesterinen EJ et al (2020) Within-season changes in habitat use of forest-dwelling boreal bats. Ecol Evol 10:4164-4174. https://doi.org/10.1002/ece3.6253

Vintulis V, Pētersons G (2014) Root cellars are important winter roosts for brown long-eared bats (Plecotus auritus) and northern bats (Eptesicus nilssonii) in Latvia. Mammalia 78:85-91. https://doi. org/10.1515/mammalia-2012-0104

Wermundsen T, Siivonen Y (2010) Seasonal variation in use of winter roosts by five bat species in south-east Finland. Open Life Sci 5:262-276. https://doi.org/10.2478/s11535-009-0063-8

Whitaker JO Jr, Rissler LJ (1992) Winter activity of bats at a mine entrance in Vermillion County, Indiana. Am Midl Nat 127:52-59. https://doi.org/10.2307/2426321

Worthy GAJ, Edwards EF (1990) Morphometric and biochemical factors affecting heat loss in a small temperate Cetacean (Phocoena phocoena) and a small tropical Cetacean (Stenella attenuata). Physiol Zool 63:432-442. https://doi.org/10.1086/physzool.63.2. 30158506

Zahn A, Kriner E (2016) Winter foraging activity of Central European Vespertilionid bats. Mamm Biol 81:40-45. https://doi.org/10. 1016/j.mambio.2014.10.005

Publisher's Note Springer Nature remains neutral with regard to jurisdictional claims in published maps and institutional affiliations. 